\title{
Detection of Respiratory Viruses in Nasopharyngeal Swab and Adenoid Tissue from Children Submitted to Adenoidectomy: Pre- and Postoperative Analysis
}

\author{
Osvaldo Vinícius Biill Primo ${ }^{1}$ Edmir Américo Lourenço ${ }^{1}$ Saulo Duarte Passos ${ }^{2}$ \\ ${ }^{1}$ Department of Otorhinolaryngology, Faculdade de Medicina de \\ Jundiaí, Jundiaí, São Paulo, Brazil \\ 2 Department of Pediatrics, Faculdade de Medicina de Jundiaí, Jundiaí, \\ São Paulo, Brazil \\ Address for correspondence Osvaldo Vinícius Biill Primo, MSc, ENT, \\ Department of Otorhinolaryngology, Faculdade de Medicina de \\ Jundiaí-SP, Rua Francisco Telles, 250-Vila Arens, Jundiaí, São Paulo \\ 13202-550, Brazil (e-mail: osvaldomed13@hotmail.com).
}

Int Arch Otorhinolaryngol 2014;18:150-154.

\begin{abstract}
Introduction The presence of respiratory viruses in lymphoid tissues of the nasopharynx and oropharynx and its impact on recurrent infections and hypertrophy of these tissues are not yet fully understood.

Objective To identify and determine the prevalence of major respiratory viruses in nasopharyngeal secretions and adenoid tissue pre- and postoperatively of children undergoing adenoidectomy.

Methods A prospective observational study was conducted in 36 patients under 12 years of age with upper airway lymphoid hypertrophy who were undergoing adenoidectomy, in which various respiratory viruses were investigated using realtime polymerase chain reaction in adenoid tissue and nasopharyngeal secretions collected preoperatively and 30 days postoperatively.

Results At least 1 viral agent was isolated in any of the samples collected in $58.3 \%$ of children and $25.9 \%$ of total samples. Respiratory viruses were identified in $33.8 \%$ of

\section{Keywords}

- viruses

- adenoids

- adenoidectomy

- child

- polymerase chain reaction preoperative nasopharyngeal specimens and in $19.8 \%$ of postoperative secretion. Of the 21 patients with positive results for any respiratory virus, $6(28.6 \%)$ had more than 1 virus. Considering all 36 respiratory viruses found, the main agent isolated was rhinovirus (27.8\%), followed by bocavirus (22.2\%).

Conclusion The virus found more frequently in all samples was rhinovirus. After removal of adenoid tissue, there was a decrease in the prevalence of the virus contained in nasopharyngeal secretion 30 days after surgery.
\end{abstract}

\section{Introduction}

The Waldeyer lymphatic ring is formed by a conglomerate of lymphoid structures comprising the pharyngeal tonsils (adenoids) and palatine tonsils, beyond the lingual and peritubal tonsils. It is strategically located at the entrance of the

received

September 10, 2013

accepted

December 2, 2013
DOI http://dx.doi.org/

10.1055/s-0034-1368135. ISSN 1809-9777. respiratory and digestive systems and is exposed to a wide variety of antigens present in air and food, which are continuously presented to the body. ${ }^{1-3}$

Hypertrophy of pharyngeal and palatine tonsils is one of the most common disorders found by otolaryngologists and is a major cause of upper airway obstruction, accounting
Copyright $\odot 2014$ by Thieme Publicações License terms Ltda, Rio de Janeiro, Brazil
(®) $\Theta \circledast$ 
for $\sim 75 \%$ of respiratory disorders in childhood, which may vary from primary snoring to severe cases of obstructive sleep apnea with cardiovascular commitment. ${ }^{4,5}$

The pathogenesis of inflammatory/infectious disease of tonsils and adenoids probably involves their anatomical location and its antigen-processing function. There is no certainty about what determines the onset of chronic infection. Viral infection with bacterial infection may be one of the triggering mechanisms of chronic infection, but the effects of the environment, personal factors, and diet, among others, may also be involved. Several studies and theories have been published based primarily on allergic mechanisms or viral and/or bacterial infectious processes. ${ }^{6-9}$

Although it is a very common health problem in daily medical practice, the presence of respiratory viruses in lymphoid tissues of the nasopharynx and oropharynx and their impact on recurrent infections and hypertrophy of these tissues are not yet fully understood and are being studied by numerous researches. Many authors have identified the presence of multiple viral agents in these tissues, latent in asymptomatic patients. ${ }^{6,10-15}$ Most of these studies in the literature are performed among symptomatic and hospitalized children with acute disease, which hampers a better understanding of this pathophysiology.

\section{Aim}

This study aims to identify and determine the prevalence of major respiratory viruses in nasopharyngeal secretions collected pre- and postoperatively and adenoid tissue of children undergoing adenoidectomy.

\section{Methods}

A prospective observational study was performed in 36 patients under 12 years of age with upper airway lymphoid hypertrophy undergoing adenoidectomy or adenotonsillectomy, assisted by the otorhinolaryngology clinic of a university hospital. The study was approved by the institutional research ethics committee (protocol number 363/2011). All parents or guardians signed a consent form after being informed of the objectives, procedures, and responsibilities of the research, as well as received answers to any questions regarding the study.

The study included children under 12 years of age with clinical and/or radiologic criteria for adenoidectomy or adenotonsillectomy (recurrent tonsillitis and/or hypertrophy of lymphoid tissues leading to upper airway obstruction). Children were excluded from the study if they had fever or any type of acute respiratory tract infection at the time of collection of biological samples, if they had craniofacial malformations, if they were immunocompromised, or if their parents did not agree with their participation in the research project.

Several respiratory viruses (influenza A and B; parainfluenza $1,2,3$, and 4; rhinovirus; respiratory syncytial virus; human bocavirus; coronaviruses; and metapneumovirus) were investigated by quantitative real-time polymerase chain reaction (q-PCR) in adenoid tissue removed surgically and nasal swab specimens collected preoperatively and at 1 month postoperative follow-up visit.
Nasal secretion was collected with the aid of a sterile metal rod nasal swab, following the rules of asepsis. The nasal cavity was previously humidified with $1 \mathrm{~mL}$ of sterile sodium chloride $0.9 \%$ solution. The swab was introduced directly into the nasal cavity without contact with the patient's skin or other region. After collecting, this swab was homogenized in microtubes containing sterile Ringer lactate solution. The adenoid tissue was obtained by cold adenoidectomy under general anesthesia by curettage of adenoid tissue. Small fragments of adenoid tissue were stored in microtubes containing virus transport media, which is a solution for transportation and storage of viruses in tissues.

After collection, the samples were transported in liquid nitrogen in microtubes to the Research Laboratory of Virology and Molecular Biology, where they were frozen at $-80^{\circ} \mathrm{C}$, and subsequently viral genetic material in the secretion and adenoid tissue was extracted according to a standardized protocol by the laboratory. After extraction, q-PCR was performed of respiratory viruses using the handset Applied Biosystems 7500 Real-Time PCR Systems (Life Technologies ${ }^{\mathrm{TM}}$, California, USA) following the manufacturer's specifications and protocols. The FTD-Respiratory-21 kit from Fast-Track Diagnostics ${ }^{\mathrm{TM}}$ (Junglinster, Luxemburg) was used to identify respiratory viruses.

The database was created using Microsoft Excel program (Microsoft, Redmond, Washington, United States). The data were analyzed using absolute $(n)$ and relative (\%) frequencies, average, and standard deviation, depending on the variable studied. The averages of continuous outcome variables were compared by the Student $t$ test. The association of the qualitative measures between groups was performed using the chi-square test or Fisher exact test to determine statistical significance. The software used for analysis was SPSS (Statistical Package for Social Sciences, IBM ${ }^{\mathrm{TM}}$, Armonk, New York, USA) version 13 and the assumed level of significance was $5 \%(p<0.05)$.

\section{Results}

The study evaluated 36 children between 3 and 12 years of age undergoing adenoidectomy or adenotonsillectomy from April 2012 to January 2013, with an average age of 7.3 years and a median of 7 years. Of these 36 children, 25 (69.4\%) were girls and 11 (30.6\%) were boys. A total of 108 pre- and postoperative nasopharyngeal specimens and adenoid tissue samples were removed surgically from these 36 patients (75 samples from girls and 33 from boys). At least 1 viral agent was isolated in any of the samples collected in $58.3 \%$ of 36 children $(n=21)$ and in $25.9 \%$ of 108 samples $(n=28)$, in $36.4 \%(n=12)$ of 33 samples of boys and $21.3 \%(n=16)$ samples from 75 girls. Of the respiratory viruses found in 36 samples, $75 \%$ ( $n=27$ ) were isolated in children under 7 years of age.

Of the 21 patients with positive results for any respiratory virus, 6 (28.6\%) had more than 1 respiratory virus. Considering the 28 positive samples, the rate of viral coinfection also was $28.6 \%(n=8)$ : 3 samples of adenoid tissue (27.3\%), 2 samples of preoperative secretion (16.7\%), and 3 samples of postoperative secretion (60\%). All coinfections were observed 
Table 1 Respiratory viruses $(n=36)$ found in 28 samples from 21 patients

\begin{tabular}{|c|c|c|c|c|c|}
\hline \multirow[t]{2}{*}{ Patient } & \multirow[t]{2}{*}{ Sex } & \multirow[t]{2}{*}{ Age } & \multicolumn{3}{|c|}{ Respiratory viruses } \\
\hline & & & Preoperative secretion & Adenoid tissue & Postoperative secretion \\
\hline 1 & Male & 11 & Rhinovirus & - & - \\
\hline 2 & Female & 5 & - & Parechovirus + Bocavirus & Parechovirus + Coronavirus 229 \\
\hline 3 & Male & 5 & Rhinovirus & - & Rhinovirus + Adenovirus \\
\hline 4 & Male & 8 & - & Enterovirus & Adenovirus \\
\hline 5 & Male & 4 & Bocavirus & - & - \\
\hline 6 & Male & 5 & Rhinovirus & Adenovirus & - \\
\hline 7 & Male & 9 & Rhinovirus & - & - \\
\hline 8 & Female & 10 & - & - & Coronavirus HKU \\
\hline 9 & Female & 6 & Rhinovirus + Influenza A & - & - \\
\hline 10 & Female & 6 & Enterovirus & - & - \\
\hline 11 & Female & 10 & - & Enterovirus & - \\
\hline 12 & Female & 4 & Rhinovirus + Bocavirus & Parechovirus & Metapneumovirus A/B + Bocavirus \\
\hline 13 & Female & 3 & - & Coronavirus 43 & - \\
\hline 14 & Male & 5 & - & Rhinovirus & - \\
\hline 15 & Female & 9 & Coronavirus HKU & - & - \\
\hline 16 & Male & 7 & Parainfluenza 4 & - & - \\
\hline 17 & Female & 4 & Rhinovirus & - & - \\
\hline 18 & Female & 5 & - & Rhinovirus + Bocavirus & - \\
\hline 19 & Female & 9 & - & Adenovirus & - \\
\hline 20 & Male & 5 & - & Bocavirus & - \\
\hline 21 & Female & 6 & Bocavirus & Parainfluenza $4+$ Bocavirus & - \\
\hline
\end{tabular}

in patients under 6 years of age, and 2 of these patients had coinfections in 2 different samples.

Respiratory viruses were found in $33.3 \%$ of preoperative nasopharyngeal specimens $(n=12)$, with a single virus isolated in $83.3 \%(n=10)$ and coinfection by 2 viral agents in $16.7 \%$ of samples $(n=2)$, totaling 14 respiratory viruses. In adenoid tissue samples, respiratory viruses were found in $30.6 \%(n=11)$ : single viral infection in $72.8 \%(n=8)$ and coinfection in $27.2 \%(n=3)$ of these positive samples (totaling 14 viruses). Of postoperative nasopharyngeal secretions, the positivity was less-in only $13.9 \%$ of samples $(n=5)$ was a respiratory virus isolated: coinfection in $60 \%(n=3)$ and single virus infection in $40 \%(n=2$; - Table 1$)$.

From the 14 respiratory viruses identified in preoperative nasopharyngeal secretions, $50 \%$ were rhinovirus $(n=7)$, present in 19\% of 36 samples tested. In adenoid tissue, respiratory viruses were identified in 14 , and the most frequent virus found was bocavirus, present in $11 \%$ of samples ( $n=4$ ), corresponding to $28.6 \%$ of the virus isolated. In nasopharyngeal secretions collected after surgery, only 8 respiratory viruses were identified, of which $25 \%(n=2)$ were adenoviruses, present in $6 \%$ of samples.

Considering all 36 respiratory viruses isolated in 108 samples evaluated, the main agent isolated was rhinovirus (27.8\%), followed by bocavirus (22.2\%). Other viruses isolated with a lower frequency were adenovirus (11.1\%), enterovi- ruses (8.3\%), parechovirus (8.3\%), coronavirus HKU (5.6\%), parainfluenza virus $4(5.6 \%)$, influenza $\mathrm{A}(2.8 \%)$, coronavirus 43 (2.8\%), coronavirus 229 (2.8\%), and metapneumovirus A/B (2.8\%). The respiratory syncytial virus was not isolated in the samples (-Table 2).

\section{Discussion}

In general, $58.4 \%$ of the patients $(n=21)$ and $25.9 \%$ of samples $(n=28)$ were positive for at least 1 respiratory virus. Studies in the literature show different prevalences, because some studies were virus-specific and others researched the prevalence of multiple respiratory viruses at the same time. Herberhold et al investigated several respiratory viruses in adenoid tissue from 30 children. The authors found a high positivity: at least 1 respiratory virus was identified in $97 \%$ of 52 samples. ${ }^{16}$ Sato et al also searched respiratory viruses in adenoid tissue and found at least 1 respiratory virus in all samples. ${ }^{17}$ In the study of Proenca-Modena et al, this positivity was $97.5 \%$, and the highest rate of viral detection was found in the adenoid tissue (85.7\%), followed by nasal secretions (78.5\%), tonsils (68.6\%), and peripheral blood (1\%). ${ }^{8}$

Considering all viruses found in this study, rhinovirus was isolated most frequently, followed by bocavirus. In the study of Herberhold et al, rhinovirus was also the most common respiratory virus, identified in $67 \%$ of samples, followed by 
Table 2 Frequency of viruses in the samples $(n=36)$

\begin{tabular}{|l|l|l|l|l|}
\hline & Preoperative secretion & Adenoid tissue & Postoperative secretion & Total \\
\hline Rhinovirus & $7(50 \%)$ & $2(14.3 \%)$ & $1(12.5 \%)$ & $10(27.7 \%)$ \\
\hline Bocavirus & $3(21.4 \%)$ & $4(28.6 \%)$ & $1(12.5 \%)$ & $8(22.2 \%)$ \\
\hline Adenovirus & $0(0 \%)$ & $2(14.3 \%)$ & $2(25 \%)$ & $4(11.1 \%)$ \\
\hline Enterovirus & $1(7.2 \%)$ & $2(14.3 \%)$ & $0(0 \%)$ & $3(8.3 \%)$ \\
\hline Parechovirus & $0(0 \%)$ & $2(14.3 \%)$ & $1(12.5 \%)$ & $3(8.3 \%)$ \\
\hline Coronavirus HKU & $1(7.2 \%)$ & $0(0 \%)$ & $1(12.5 \%)$ & $2(5.6 \%)$ \\
\hline Parainfluenza 4 & $1(7.2 \%)$ & $1(7.1 \%)$ & $0(0 \%)$ & $2(5.6 \%)$ \\
\hline Influenza A & $1(7.2 \%)$ & $0(0 \%)$ & $0(0 \%)$ & $1(2.8 \%)$ \\
\hline Coronavirus 43 & $0(0 \%)$ & $1(7.1 \%)$ & $0(0 \%)$ & $1(2.8 \%)$ \\
\hline Coronavirus 229 & $0(0 \%)$ & $0(0 \%)$ & $1(12.5 \%)$ & $1(2.8 \%)$ \\
\hline Metapneumovirus A/B & $0 \%$ & $0(0 \%)$ & $1(12.5 \%)$ & $1(2.8 \%)$ \\
\hline Total & $14(100 \%)$ & $14(100 \%)$ & $8(100 \%)$ & $36(100 \%)$ \\
\hline
\end{tabular}

bocavirus in $53 \%$, similar to our study but with different prevalences. ${ }^{16}$ In another study, adenovirus was the most common viral agent, isolated in $47.1 \%$ of patients, followed by enterovirus (40.5\%), rhinovirus (38\%), and bocavirus (29.8\%). ${ }^{8}$ In the study from Sato et al, adenovirus was the most common viral agent, present in $80 \%$ of samples. ${ }^{17}$ Alkhalaf et al analyzed 106 palatine and pharyngeal tonsils of 57 patients undergoing routine tonsillectomy or adenoidectomy. Employing the technique of real-time polymerase chain reaction, the authors identified 84 samples (72.4\%) positive for adenovirus. $^{18}$

In this study, $28.6 \%(n=6)$ of patients with positive results presented coinfection with 2 viral agents, and 2 patients had viral coinfection in 2 samples, totaling 8 samples. Bocavirus was isolated in $75 \%(n=6)$ of the coinfections. Rhinovirus was identified in all coinfections of preoperative nasopharyngeal secretions $(n=2)$, and bocavirus was isolated in all coinfections in adenoid tissue $(n=3)$. In coinfections of preoperative nasopharyngeal secretions, there was no predominant viral agent.

Herberhold et al found multiple respiratory viruses in $83 \%$ of samples evaluated. ${ }^{16}$ In the study of Proenca-Modena et al, the rate of coinfection was $69.5 \%$. The authors evaluated 121 children who underwent adenotonsillectomy and found high rates of viral detection in adenotonsillar tissues. The authors were researching respiratory viruses on palatine tonsils, adenoid tissue, nasal secretions, and peripheral blood but did not evaluate the postoperative nasopharyngeal secretions. ${ }^{8}$

Review of the literature found no studies comparing the prevalence of the virus in nasopharyngeal secretions pre- and postoperatively. Some studies revealed that the adenoid tissue may be a reservoir of viruses. Comparing the prevalence of virus pre- and postoperatively, we aimed to analyze a possible influence of adenoid tissue in the maintenance of these viruses in secretions. After the analysis of preoperative nasopharyngeal samples, this study found that $33.3 \%$ of patients $(n=12)$ were positive for at least 1 respiratory virus.
Of the 14 respiratory viruses isolated, 50\% were rhinovirus. After surgery, the positivity of respiratory viruses in nasopharyngeal secretions of these patients decreased: in only $13.9 \%$ of patients ( $n=5)$ was at least 1 viral agent isolated in the sample. In the postoperative secretions, 8 respiratory viruses were detected, and adenoviruses were identified in 2 patients. These results suggest a decrease in the prevalence of the virus after surgery ( $p=0.0522)$. However, the number of patients in the study is relatively small, and a greater number of samples are required to confirm or reject this hypothesis.

In addition to the small sample size, a seasonal effect may contribute to the discrepancies found between our results and other studies in the literature. We know that some respiratory viruses are found in certain periods of the year; however, as we have seen, apparently the virus may persist in the adenoid tissue and nasopharyngeal secretions even after the symptomatic phase of the disease. The climatic conditions of each region, air quality, and population characteristics may also contribute to a greater or lesser circulation of respiratory viruses in a given region and time of year.

The present study revealed that some patients with hypertrophy of pharyngeal tonsil exhibit respiratory viruses detected on nasopharyngeal and adenoid tissue, even if asymptomatic. These data suggest that the persistence or latency of respiratory viruses on nasopharyngeal and adenoid tissue after an acute infectious process may be related to the pathogenesis of lymphoid hypertrophy of the upper airways and that these tissues may function as a reservoir of virus, with possible influence on its transmission in the community. After adenoidectomy, a decrease in respiratory viruses present in nasopharyngeal secretions was observed. From this finding, we can infer a lower chance of occurrence of infections as well as secondary superinfections and virus transmission to contacts after surgery. Considering the age group studied, in which there is a greater interpersonal contact, this decrease in the circulation of respiratory viruses becomes important for public health, with positive impact on the quality of life of these children. 


\section{Conclusion}

The rhinovirus was the most frequently found virus in all samples, followed by bocavirus. After removal of adenoid tissue, there was a decrease in the prevalence of viruses in nasopharyngeal secretions.

\section{References}

1 Dias EP, Rocha ML, Carvalho MOO, Amorim LMF. Detecção do vírus Epstein-Barr em tonsilites recorrentes. Braz J Otorhinolaryngol (Engl Ed) 2009;75(1):30-34

2 Dell'Aringa AR, Juares AJC, deMelo C, et al. Análise histopatológica de produtos de adenotonsilectomia de janeiro de 2001 a maio de 2003. Braz J Otorhinolaryngol 2005;71(1):18-22

3 Mogoantă CA, Ioniță E, Pirici D, et al. Chronic tonsillitis: histological and immunohistochemical aspects. Rom J Morphol Embryol 2008;49(3):381-386

4 Llombart M, Chiner E, Gómez-Merino E, et al. Síndrome de apneashipopneas durante el sueño en población infantil: diferencias en su expresión entre niños con hipertrofia amigdalar y con enfermedad concomitante. Arch Bronconeumol 2007;43(12):655-661

5 Beraldin BS, Rayes TR, Villela PH, Ranieri DM. Assessing the impact adenotonsillectomy has on the lives of children with hypertrophy of palatine and pharyngeal tonsils. Braz J Otorhinolaryngol 2009; 75(1):64-69

6 Frankel SS, Tenner-Racz K, Racz P, et al. Active replication of HIV-1 at the lymphoepithelial surface of the tonsil. Am J Pathol 1997; 151(1):89-96

7 Huang SW, Giannoni C. The risk of adenoid hypertrophy in children with allergic rhinitis. Ann Allergy Asthma Immunol $2001 ; 87(4): 350-355$
8 Proenca-Modena JL, Pereira Valera FC, Jacob MG, et al. High rates of detection of respiratory viruses in tonsillar tissues from children with chronic adenotonsillar disease. PLoS ONE 2012;7(8):e42136

9 Drago L, Esposito S, De Vecchi E, et al. Detection of respiratory viruses and atypical bacteria in children's tonsils and adenoids. J Clin Microbiol 2008:46(1):369-370

10 Roush KS, Domiati-Saad RK, Margraf LR, et al. Prevalence and cellular reservoir of latent human herpesvirus 6 in tonsillar lymphoid tissue. Am J Clin Pathol 2001;116(5):648-654

11 Chen R, Sehr P, Waterboer T, et al. Presence of DNA of human papillomavirus 16 but no other types in tumor-free tonsillar tissue. J Clin Microbiol 2005;43(3):1408-1410

$12 \mathrm{Lu} \mathrm{X}$, Gooding LR, Erdman DD. Human bocavirus in tonsillar lymphocytes. Emerg Infect Dis 2008;14(8):1332-1334

13 Suvilehto J, Roivainen M, Seppänen M, et al. Rhinovirus/enterovirus RNA in tonsillar tissue of children with tonsillar disease. J Clin Virol 2006;35(3):292-297

14 Endo Y, Carroll KN, Ikizler MR, Wright PF. Growth of influenza A virus in primary, differentiated epithelial cells derived from adenoids. J Virol 1996;70(3):2055-2058

15 Endo LH, Ferreira D, Montenegro MC, et al. Detection of EpsteinBarr virus in tonsillar tissue of children and the relationship with recurrent tonsillitis. Int J Pediatr Otorhinolaryngol 2001;58(1): 9-15

16 Herberhold S, Eis-Hübinger AM, Panning M. Frequent detection of respiratory viruses by real-time PCR in adenoid samples from asymptomatic children. J Clin Microbiol 2009;47(8):2682-2683

17 Sato M, Li H, Ikizler MR, et al. Detection of viruses in human adenoid tissues by use of multiplex PCR. J Clin Microbiol 2009; 47(3):771-773

18 Alkhalaf MA, Guiver M, Cooper RJ. Prevalence and quantitation of adenovirus DNA from human tonsil and adenoid tissues. J Med Virol 2013;85(11):1947-1954 